\title{
Review of Etiology of Posterior Open Bite: Is There a Possible Genetic Cause?
}

This article was published in the following Dove Press journal:

Clinical, Cosmetic and Investigational Dentistry

\author{
Wei Huang ${ }^{1} *$ \\ Bo Shan iD ${ }^{2, *}$ \\ Brittany S Ang' \\ Jennifer Kol \\ Richard D Bloomstein (D) \\ Thomas J Cangialosi' \\ 'Department of Orthodontics, Rutgers \\ School of Dental Medicine, Newark, N \\ 07I03, USA; ${ }^{2}$ School of Public Health, \\ Rutgers University, Newark, NJ, 07103, \\ USA
}

*These authors contributed equally to this work
Correspondence: Wei Huang

Assistant Professor, Department of

Orthodontics, Rutgers School of Dental

Medicine, 90 Bergen Street,

Orthodontics/D884/Wei Huang, Newark, NJ 07103, USA

Tel + I 973-972-7895

Fax +1 973-972-0526

Email wei.huang.ortho@rutgers.edu

\begin{abstract}
Posterior open bite (POB) is one of the most severe malocclusions that can impair patients' masticatory functions, yet it is also a condition that is poorly understood and not well studied. Most reported cases are either sporadic or idiosyncratic with a diverse yet poorly understood etiology. Although primary failure of eruption (PFE), lateral tongue thrust, and certain medical syndromes or pathology of the temporomandibular joints have all been shown to cause POB, the complex interplay of environmental and genetic factors makes its etiopathogenesis a difficult subject to understand and investigate. Here, we provide a comprehensive review of the etiology of posterior open bite. Additionally, a genetic cause for POB is proposed through a report of an apparently non-syndromic familial case series with high $\mathrm{POB}$ penetrance across two generations. Further investigations of the gene(s) and mechanism(s) involved can not only provide a unique opportunity to better understand POB and the intricate muscular-occlusal relationship, but also offer powerful insight into the most effective approaches to clinical management of these (and potentially other) malocclusions.
\end{abstract} Keywords: posterior open bite, etiology, genetic, malocclusion

\section{Etiology of Posterior Open Bite}

Posterior open bite (POB) is one of the most difficult to treat clinical entities that can severely impair a patient's masticatory function. However, it is also a condition that is not well understood and has not been well studied. It is described as a lack of posterior occlusal contact and frequently is accompanied by facial asymmetry, ${ }^{1-3}$ failure of teeth to erupt, ${ }^{4-9}$ temporomandibular disorders, ${ }^{2,10-12}$ or medical syndromes. ${ }^{13,14}$ The prevalence of POB is unknown but low, and despite its severe functional consequences the etiology remains unclear. Most reported cases are sporadic, idiosyncratic, or caused by primary failure of eruption (PFE). Here, we provide a comprehensive overview of the etiology of POB.

\section{Failure of Tooth Eruption}

POB can be a consequence of eruption failure of teeth, including mechanical failure of eruption (MFE) and PFE. ${ }^{6}$ MFE is most often caused by ankylosis, where the cementum is fused to the alveolar bone resulting in a tooth eruption defect. It usually affects one tooth and may respond to surgical luxation and orthodontic forces. ${ }^{8} \mathrm{PFE}$, on the other hand, is incomplete eruption of non-ankylosed teeth due to a defective eruption mechanism. ${ }^{4}$ PFE typically affects multiple posterior teeth with all teeth distal to the most mesially affected tooth exhibiting similar infraocclusion. ${ }^{4}$ Bilateral manifestation of PFE appears to be less than two times more frequent than unilateral. ${ }^{15}$ These teeth 
will become ankylosed if there is an attempt to extrude them orthodontically. ${ }^{4}$ Therefore, treatment options for PFE often include extraction followed by prosthetic replacement or possible segmental osteotomy. Mutations in several genes, such as parathyroid hormone receptor 1 (PTH1R) $)^{15,16}$ and histone methyltransferase 2C (KMT2C), have been identified to be strongly associated with PFE. ${ }^{17}$ Thus, for suspected PFE cases, genetic screening is recommended to facilitate diagnosis and treatment decisions.

\section{Tongue and Masseter}

A lateral tongue-thrusting habit may be a direct environmental cause of POB. Its presence has been described in several case reports and postulated to be etiological to regional $\mathrm{POB} .{ }^{18-20}$ However, many of these cases also present with another POB contributor such as unilateral mandibular hyperplasia or Class III skeletal relationship with posterior crossbite. Therefore, it can be difficult to determine whether the POB is due to the tongue thrust or the tongue is just malpositioned as a secondary effect of existing POB due to the lack of contact with the posterior teeth, as frequently seen in edentulous patients. Controlled studies are still lacking to address this question. Nonetheless, the tongue-thrusting habit creates a mechanical interference in posterior tooth eruption. ${ }^{21}$ Therefore, control of the habit and myofunctional therapy are generally needed for successful treatment and retention for many POB cases. ${ }^{21}$

Interestingly, the masseter muscle with or without a tongue habit may play an important etiological role in certain rare POB conditions. Duchenne muscular dystrophy (DMD) is a progressive genetic neuromuscular disorder characterized by deterioration of muscle strength and increasingly difficult ambulation starting in early childhood. ${ }^{22,23}$ Patients with DMD show a high percentage of $\mathrm{POB}$ occurrence without vertical skeletal aberrations. ${ }^{22,24}$ Their decreased tonus of masseter and enlarged hypotonic tongue are likely the cause of the POB. ${ }^{23,24}$ In a case report of post-traumatic trigeminal neuropathy caused by an orbital stab wound, unilateral POB was observed to be correlated with the atrophy of the ipsilateral masseter muscle, ${ }^{25}$ indicating a possible role of masseter in POB etiology.

\section{TMJ}

Many pathological changes of the temporomandibular joints (TMJ) can lead to POB as a result of displacement of the mandibular condyle. A sudden appearance of POB can be caused by joint effusion from mandibular trauma or an acute episode of rheumatoid arthritis, ${ }^{10}$ as well as hemarthrosis from anticoagulant therapy ${ }^{26}$ or hemophilia. ${ }^{27}$ Posterior disc displacement, ${ }^{28,29}$ posterior displacement of the posterior fragment after a TMJ disc fracture ${ }^{12}$ and increased posterior thickness of the retrodiscal tissue ${ }^{11}$ can all cause a mandibular closing disturbance just before complete mouth closure, hence the occurrence of POB.

Unilateral condylar hyperplasia is a condition characterized by excessive growth and enlargement of one mandibular condyle. ${ }^{30}$ When the vertical overgrowth of the affected side is met with incomplete compensatory downward growth of the maxilla, ipsilateral POB may occur. ${ }^{2}$

Certain TMJ-related therapies such as arthroscopic disc repositioning and placement of an anterior repositioning splint have been shown to have a common occurrence of POB. ${ }^{31,32}$ While surgical overcorrection of the displaced disc and misshapen disc is the possible reason for postarthroscopy $\mathrm{POB},{ }^{31}$ recapture of the disc in the correct position at mouth closing is considered causal for $\mathrm{POB}$ in some splint cases. ${ }^{32}$

\section{Mandibular Advancement Therapy}

Patients who use functional mandibular advancement appliances to manage obstructive sleep apnea/hypopnea syndrome often present with a POB side effect. ${ }^{33}$ Although the occurrence ranges anywhere from $0 \%(6$ months treatment) to $51 \%$ (11 years treatment), it appears that the longer the treatment, the higher the POB incidence among these patients. ${ }^{34-39}$ As these appliances hold the mandible in a forward and vertically opened position to prevent the pharyngeal airway from collapsing, ${ }^{34}$ transient contracture of the inferior lateral pterygoid muscle, forward and downward positioning of lower arch and protrusion of mandibular incisors have been suggested to contribute to the occurrence of $\mathrm{POB} .{ }^{34-36,40}$

\section{Syndromes and Class III}

Patients with amelogenesis imperfecta (AI), ${ }^{41,42}$ achondroplasia, ${ }^{14}$ Apert Syndrome, ${ }^{13}$ and $\mathrm{DMD}^{22,23}$ have all been reported to have POB as part of their craniofacial manifestations. AI in particular shows a high percentage of POB occurrence. ${ }^{41,42}$ However, the mechanisms related to these conditions remain unknown.

Additionally, several case reports have documented concomitant $\mathrm{POB}$ in Class III malocclusions (skeletal and/or dental). ${ }^{1,3,18,20,43-46}$ The POB, however, occurs often in the presence of other factors such as tongue thrust habits, ${ }^{18,20}$ vertical underdevelopment of the dentoalveolar process, ${ }^{18}$ a narrow maxilla with mandibular asymmetry, ${ }^{1}$ 
a history of cleft palate, ${ }^{46}$ perioral muscle strain, ${ }^{43}$ and multiple missing teeth. ${ }^{44}$

\section{Proposing a Genetic Cause of Posterior Open Bite}

Despite all the reported cases of POB, the etiology seems diverse and not well understood. The interplay between genetics and environmental factors often complicates the study of its underlying causes. In addition, it is unclear how much of a role genetics actually plays. Can genetics be a more direct etiological factor for POB without causing any other major craniofacial defects as seen in many syndromic conditions? Although there is no report so far on any genetic cause of POB in the literature (except for those indirectly caused by PFE), the possibility exists.

\section{A Family of POB Cases}

In the orthodontic clinic at Rutgers School of Dental Medicine, there is an interesting pedigree of POB cases with high penetrance across two generations but no syndromic conditions are reported. All patients have given their written consent for the publication of their case details. Institutional IRB approval has been granted by Rutgers University. Patient MM1, MM2 and MM3 are three Caucasian siblings all affected by POB. Their age at initial records was 16 years 1 month, 20 years 9 months and 24 years 9 months, respectively. As shown in Figures 1-3, all siblings presented with straight to mildly concave profiles, with moderately to severely retruded upper and lower lips. Their facial proportions (thirds and fifths) were relatively well balanced, but their lip muscle tones were high both in appearance and upon clinical examination. Lateral tongue thrust was detected among all three patients with clear scalloped dental marks on both sides of the tongue. The size of the tongue appeared to be within normal limits. All siblings had a Class II molar and canine relationships with significantly retroclined upper and lower incisors, a constricted upper arch, deep overbite, and mild to severe crowding. Patient MM2 and MM3 both presented with a mild Class II skeletal relationship while patient MM1 had a very mild Class III skeletal pattern. Patient MM1 was hypodivergent, MM2 normodivergent, and MM3 hyperdivergent vertically. The patients denied having any medical conditions or syndromes. However, patient MM1 was reported to have had failure to thrive as a newborn.

Upon inquiry into the family history, the mother and aunt of the three siblings also had similar POB, although their dental records were not available. None of the family members on the father's side demonstrated any POB. Patient MM2, MM3, the mother and aunt received orthodontic treatment years ago with successful closure of the POB, but relapse occurred in patient MM2 and the mother at the time MM2 presented for initial records which was the reason for MM2's second orthodontic treatment request.
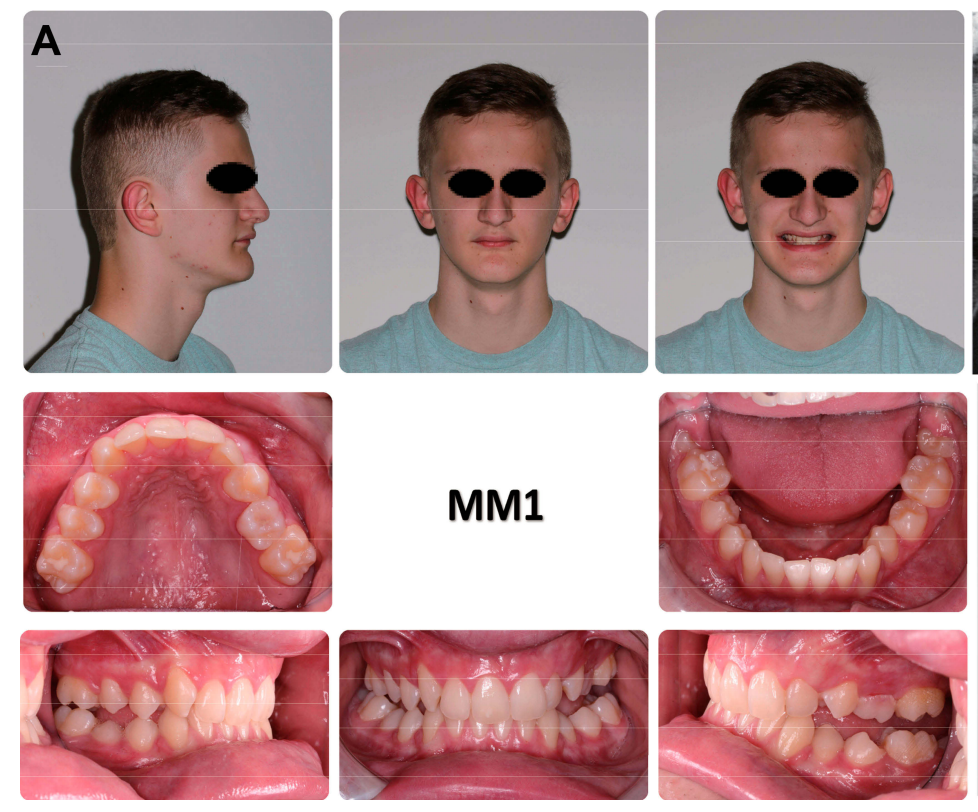
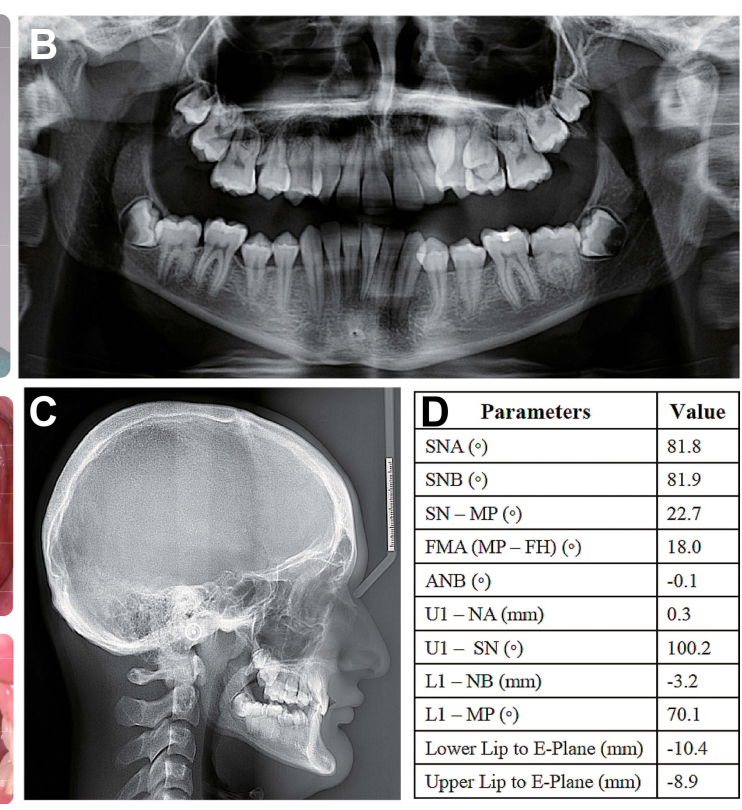

\begin{tabular}{|l|l|}
\hline D Parameters & Value \\
\hline SNA $\left({ }^{\circ}\right)$ & 81.8 \\
\hline SNB $\left({ }^{\circ}\right)$ & 81.9 \\
\hline SN - MP $(\circ)$ & 22.7 \\
\hline FMA $(\mathrm{MP}-\mathrm{FH})\left({ }^{\circ}\right)$ & 18.0 \\
\hline ANB $(\circ)$ & -0.1 \\
\hline U1 - NA $(\mathrm{mm})$ & 0.3 \\
\hline U1 - SN $(\circ)$ & 100.2 \\
\hline L1 - NB $(\mathrm{mm})$ & -3.2 \\
\hline L1 - MP $(\circ)$ & 70.1 \\
\hline Lower Lip to E-Plane $(\mathrm{mm})$ & -10.4 \\
\hline Upper Lip to E-Plane $(\mathrm{mm})$ & -8.9 \\
\hline
\end{tabular}

Figure I Pre-treatment records of patient MMI: (A) extraoral and intraoral photos; (B) panoramic radiograph; (C) cephalometric radiograph; (D) cephalometric measurements. 

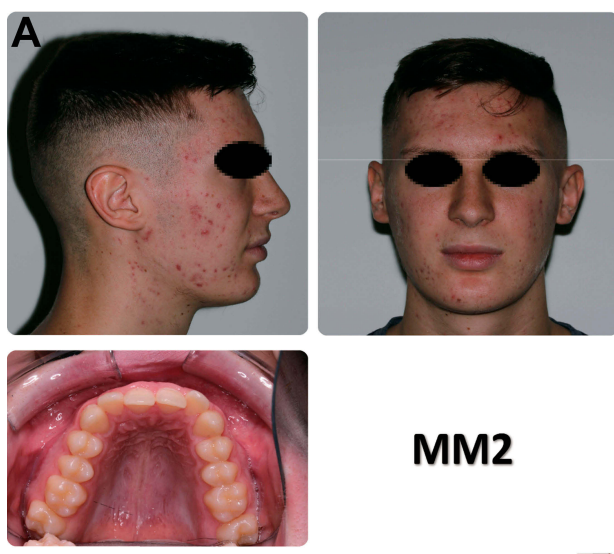

MM2
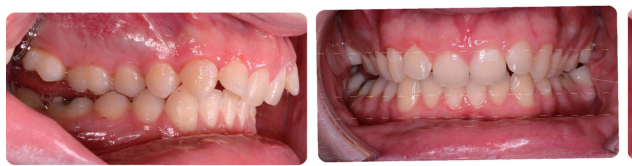
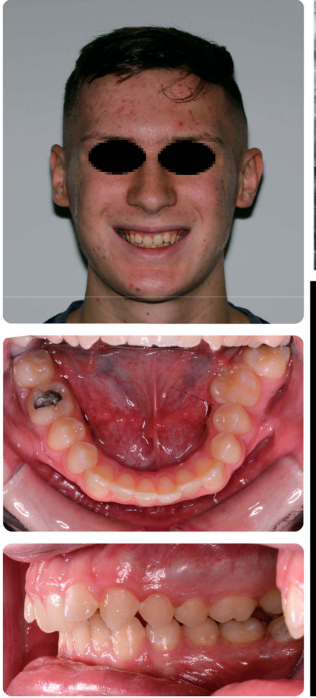

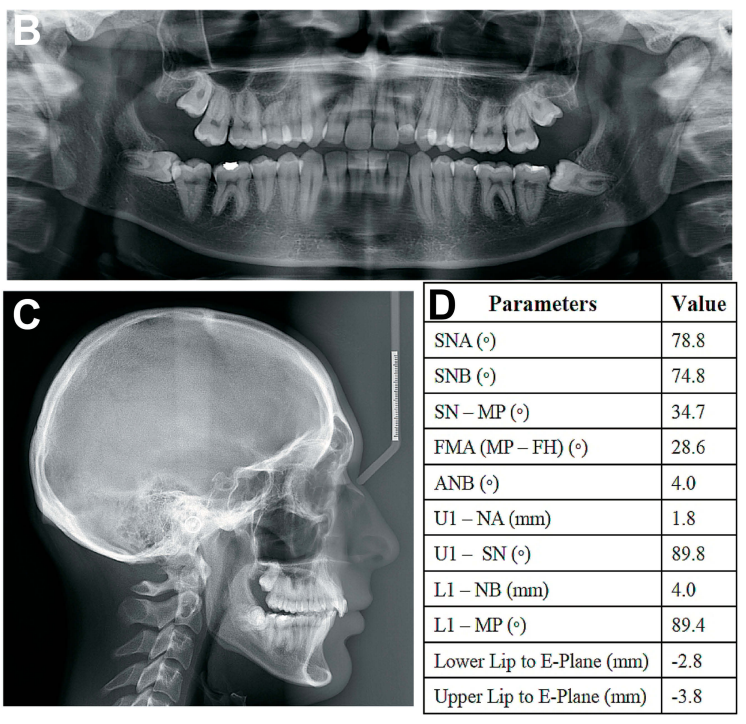

Figure 2 Pre-treatment records of patient MM2: (A) extraoral and intraoral photos; (B) panoramic radiograph; (C) cephalometric radiograph; (D) cephalometric measurements.
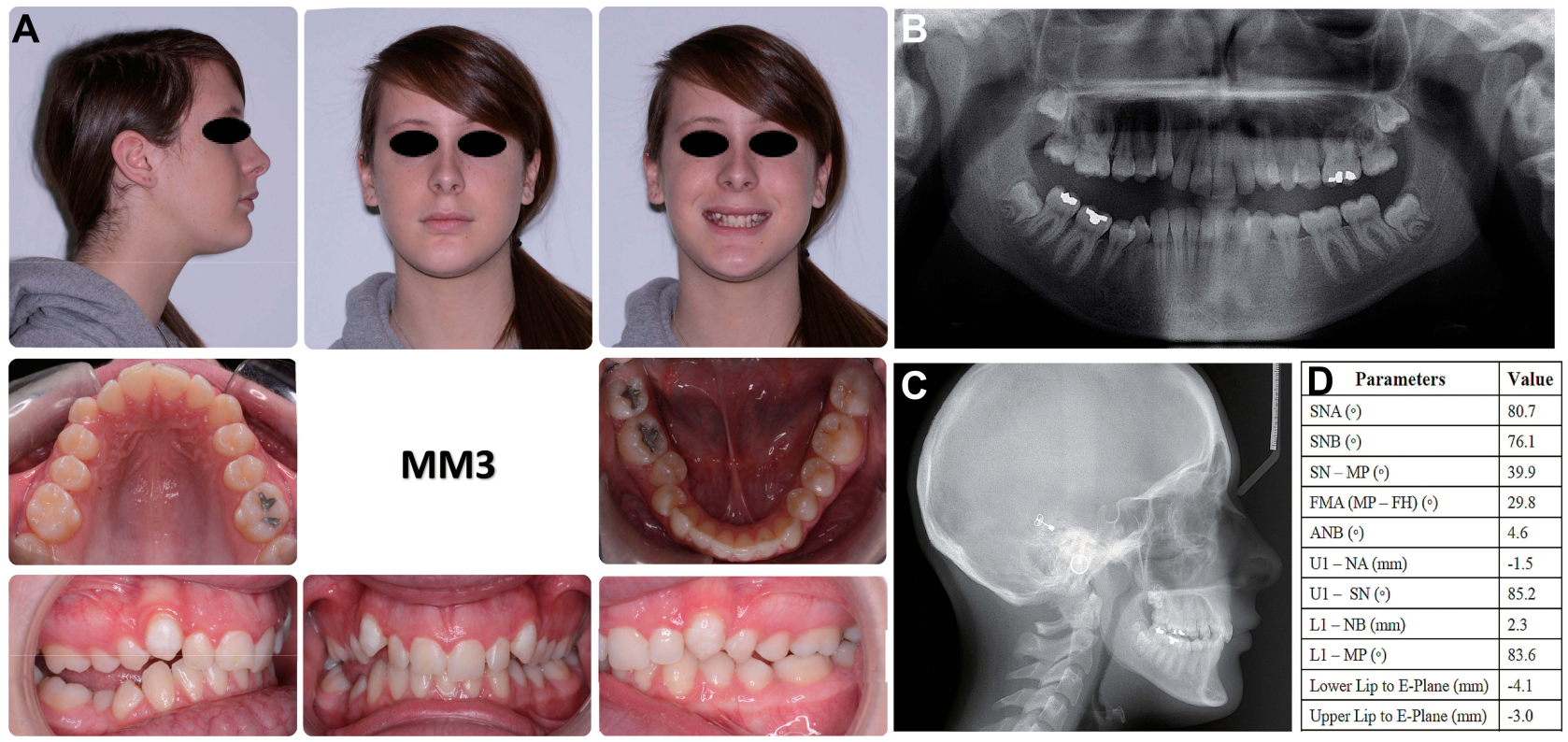

\begin{tabular}{|l|l|}
\hline D Parameters & Value \\
\hline SNA $\left({ }^{\circ}\right)$ & 80.7 \\
\hline $\mathrm{SNB}\left({ }^{\circ}\right)$ & 76.1 \\
\hline $\mathrm{SN}-\mathrm{MP}\left({ }^{\circ}\right)$ & 39.9 \\
\hline FMA $(\mathrm{MP}-\mathrm{FH})\left({ }^{\circ}\right)$ & 29.8 \\
\hline ANB $\left({ }^{\circ}\right)$ & 4.6 \\
\hline $\mathrm{U} 1-\mathrm{NA}(\mathrm{mm})$ & -1.5 \\
\hline $\mathrm{U} 1-\mathrm{SN}\left({ }^{\circ}\right)$ & 85.2 \\
\hline L1 - NB $(\mathrm{mm})$ & 2.3 \\
\hline L1 - MP $\left({ }^{\circ}\right)$ & 83.6 \\
\hline Lower Lip to E-Plane $(\mathrm{mm})$ & -4.1 \\
\hline Upper Lip to E-Plane $(\mathrm{mm})$ & -3.0 \\
\hline
\end{tabular}

Figure 3 Pre-treatment records of patient MM3: (A) extraoral and intraoral photos; (B) panoramic radiograph; (C) cephalometric radiograph; (D) cephalometric measurements.

This interesting family tree (Figure 4) of POB shows high generation penetrance and strongly indicates that there is a dominant genetic etiopathogenic factor involved. Because patient MM2, MM3 and the mother have all received previous treatment with successful closure of their POB, PFE and ankylosis can be excluded as an etiologic factor. The striking similarity of retruded upper and lower lips, increased lip muscle tones, significantly retroclined upper and lower incisors and lateral tongue thrust among the three siblings leads to our hypothesis that a dramatically increased lip muscle tone might be the direct target effect of the suspected genetic causal element. Increased lower lip pressure/activity has been well known to cause upper incisors retroclination in Class II Division 2 patients. ${ }^{47,48}$ Therefore, taut lip muscles could well cause retroclination of both upper and lower incisors, which would in turn reduce the anterior-posterior length of both arches. Shortened arches could restrain the tongue to a more posterior and lateral position leading to increased lateral tongue pressure, lateral tongue thrust/posture and ultimately POB. Alternatively, the genetic factor 


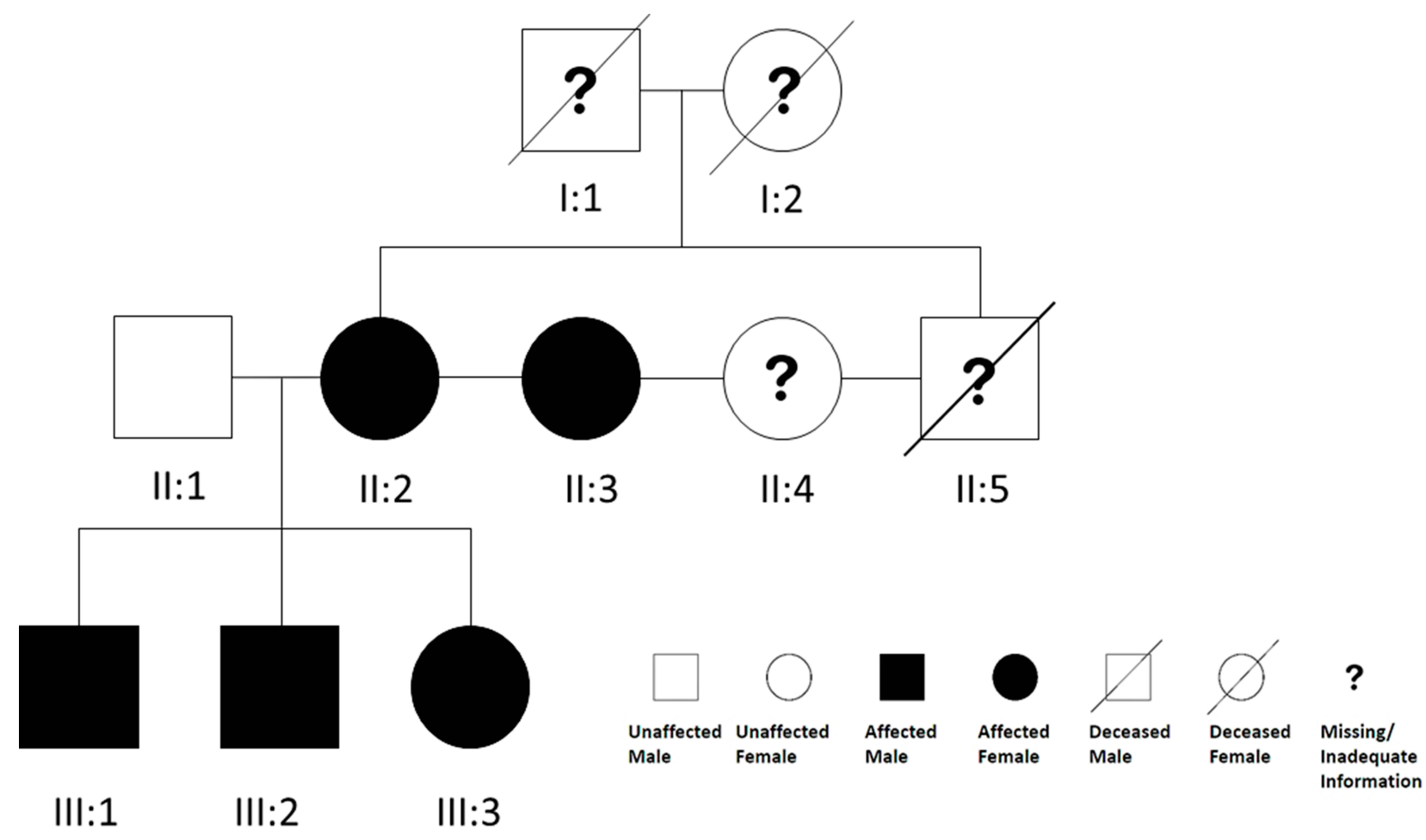

Figure 4 Pedigree of the $M$ family.

could also lead to the POB through a different mechanism while the tongue thrust/posture could simply be a secondary effect. Further studies through genetic linkage analysis or whole genome sequencing may help identify the underlying genetic factor of this pedigree of $\mathrm{POB}$, and lay the foundation for better understanding of the mechanisms.

\section{Discussion}

Genetic studies of the etiology of malocclusion have been mostly focused on syndromic conditions. Many single gene syndromic disorders present with craniofacial and oral manifestations, such as Apert's syndrome, Treacher Collins syndrome and cleidocranial dysplasia, caused by mutations in fibroblast growth factor receptor 2 (FGFR2), treacle ribosome biogenesis factor 1 (TCOF1) and Runtrelated transcription factor 2 (RUNX2), respectively. ${ }^{49,50}$ Frequently, malocclusions which occur in these disorders are part of and secondary to a complex pattern of multiple dentofacial defects. Although no syndrome has been reported for the POB subjects reported here, it is possible that a syndromic condition with high penetrance and very low expressivity might be involved.

Non-syndromic mandibular prognathism is one of the few malocclusions that appears to have a strong genetic component without any other medical and/or dental defects. ${ }^{51}$ Chromosomes 1, 4, 6, 14 and 19 have all been shown to harbor genes that confer susceptibility, ${ }^{52-55}$ with Matrilin- $1,{ }^{56}$ ADAMTS $1,{ }^{57}$ COL2A $1^{58}$ and EPB $41^{59}$ known to be strongly associated with the condition. Many of the genetic components have been reported to be involved in craniofacial bone development as well as in the function of masticatory muscles, the condyles and growth hormones. ${ }^{55,56,60-62}$ This has shed light on the multi-mechanistic nature of many mandibular prognathism conditions, and has provided important indications for the multi-focus (rather than just the bone) approach to clinical treatment and retention.

The complex interplay of genetic and environmental factors makes the pathogenic mechanisms of malocclusion a difficult matter to dissect. Therefore, unusual hereditary non-syndromic malocclusions, such as this familial POB case series, offer a rare and unique opportunity for pinpointing important etiopathogenic factors, biochemical pathways, and mechanisms that would have been otherwise impossible to identify. Discovering the gene(s) involved and its function can thus not only advance our understanding of the cause and mechanisms of POB and help lay the foundation for better treatment strategies and outcomes. It could also provide powerful insight into the function of other gene products that interact with the identified gene(s). This, in turn, can 
help identify critical pathogenic pathways that are utilized by other non-genetic etiological factors for POB as well as many other malocclusions or oral conditions. A great example of how the study of a rare genetic disorder can have much broader applications is the early work on familial hypercholesterolemia, which led to the development of statins, the blood cholesterol-lowering drugs that are now among the most widely prescribed drugs in medicine. ${ }^{63-65}$ With today's vast information on human genome sequences, large databases and advanced genetic and molecular tools, the knowledge gleaned from a seemingly isolated familial POB series may impact the understanding of physiology and pathogenesis in ways which were unfathomable previously.

\section{Conclusion}

POB is one of the most challenging clinical entities that can severely impair a patient's masticatory functions. The etiology of POB appears diverse and poorly understood with mostly case reports. Several conditions including PFE, ankylosis, tongue habits or masseter dystrophy, TMJ-related pathology and treatment, mandibular advancement therapy, as well as certain syndromes such as AI can all contribute to the occurrence of POB. Additionally, we report a non-syndromic familial case series with high $\mathrm{POB}$ penetrance across two generations and propose a possible genetic cause or predisposition for $\mathrm{POB}$.

\section{Disclosure}

Wei Huang and Bo Shan are co-first authors for this study. The authors report no conflicts of interest in this work.

\section{References}

1. Bergamo AZ, Andrucioli MC, Romano FL, Ferreira JT, Matsumoto MA. Orthodontic-surgical treatment of Class III malocclusion with mandibular asymmetry. Braz Dent J. 2011;22(2):151-156. doi:10.1590/S0103-64402011000200011

2. Ha SW, Choi JY, Baek SH. Correction of unilateral condylar hyperplasia and posterior open bite with proportional condylectomy and fixed orthodontic treatment. Angle Orthodontist. 2019;90(1):144-158.

3. Chung KR, Ahn HW, Kim SJ, Lee KB, Kim SH. Correction of collapsed occlusion with degenerative joint disease focused on the mandibular arch and timely relocation of a miniplate. Am J Orthod Dentofacial Orthop. 2012;141(3):e53-e63. doi:10.1016/j.ajodo.2011. 05.024

4. Proffit WR, Vig KW. Primary failure of eruption: a possible cause of posterior open-bite. Am J Orthod. 1981;80(2):173-190. doi:10.1016/ 0002-9416(81)90217-7

5. Ireland AJ. Familial posterior open bite: a primary failure of eruption. Br J Orthod. 1991;18(3):233-237. doi:10.1179/bjo.18.3.233

6. Frazier-Bowers SA, Koehler KE, Ackerman JL, Proffit WR. Primary failure of eruption: further characterization of a rare eruption disorder. Am J Orthod Dentofacial Orthop. 2007;131(5):578.e571-511. doi:10.1016/j.ajodo.2006.09.038
7. Atobe M, Sekiya T, Tamura K, Hamada Y, Nakamura Y. Severe lateral open bite caused by multiple ankylosed teeth: a case report. Oral Surg Oral Med Oral Pathol Oral Radiol Endod. 2009;107(4): e14-e20. doi:10.1016/j.tripleo.2008.12.029

8. Smith CP, Al-Awadhi EA, Garvey MT. An atypical presentation of mechanical failure of eruption of a mandibular permanent molar: diagnosis and treatment case report. Eur Arch Paediatr Dent. 2012;13(3):152-156. doi:10.1007/BF03262863

9. Pilz P, Meyer-Marcotty P, Eigenthaler M, Roth H, Weber BH, Stellzig-Eisenhauer A. Differential diagnosis of primary failure of eruption (PFE) with and without evidence of pathogenic mutations in the PTHR1 gene. J Orofac Orthop. 2014;75(3):226-239. doi:10.1007/s00056-014-0215-y

10. Marinho LH, McLoughlin PM. Lateral open bite resulting from acute temporomandibular joint effusion. $\mathrm{Br} J$ Oral Maxillofac Surg. 1994;32(2):127-128. doi:10.1016/0266-4356(94)90146-5

11. Hasegawa T, Shibuya Y, Minamikawa T, Komori T. Two cases of posterior open bite caused by the thickness of retrodiscal tissue in the temporomandibular joint. Int J Oral Maxillofac Surg. 2014;43 (9):1104-1107. doi:10.1016/j.ijom.2014.05.002

12. Melis M, Di Giosia M, Secci S. Temporomandibular joint disk fracture: a case report. Cranio. 2011;29(3):227-231. doi:10.1179/crn.2011.032

13. Soancă A, Dudea D, Gocan H, Roman A, Culic B. Oral manifestations in Apert syndrome: case presentation and a brief review of the literature. Rom J Morphol Embryol. 2010;51(3):581-584.

14. Celenk P, Arici S, Celenk C. Oral findings in a typical case of achondroplasia. J Int Med Res. 2003;31(3):236-238. doi:10.1177/ 147323000303100311

15. Hanisch M, Hanisch L, Kleinheinz J, Jung S. Primary failure of eruption (PFE): a systematic review. Head Face Med. 2018;14(1):5. doi:10.1186/s13005-018-0163-7

16. Decker E, Stellzig-Eisenhauer A, Fiebig BS, et al. PTHR1 loss-of-function mutations in familial, nonsyndromic primary failure of tooth eruption. Am J Hum Genet. 2008;83(6):781-786. doi:10.1016/j.ajhg.2008.11.006

17. Assiry AA, Albalawi AM, Zafar MS, et al. KMT2C, a histone methyltransferase, is mutated in a family segregating non-syndromic primary failure of tooth eruption. Sci Rep. 2019;9(1):16469. doi:10.1038/s41598-019-52935-7

18. Aras I, Olmez S, Akay MC, Oztürk VO, Aras A. Treatment of lateral open bite with vertical dentoalveolar distraction osteogenesis. Am J Orthodontics Dentofacial Orthopedics. 2015;148(2):321-331. doi:10.1016/j.ajodo.2014.07.028

19. Mitani H. Unilateral mandibular hyperplasia associated with a lateral tongue thrust. Angle Orthod. 1976;46(3):268-275. doi:10.1043/00033219(1976)046<0268:UMHAWA >2.0.CO;2

20. Park JH, Yu J, Chae JM. Lateral open bite and crossbite correction in a Class III patient with missing maxillary first premolars. $\mathrm{Am} \mathrm{J}$ Orthodontics Dentofacial Orthopedics. 2017;152(1):116-125. doi:10.1016/j.ajodo.2017.04.004

21. Cabrera M, Cabrera CA, de Freitas KM, Janson G, de Freitas MR. Lateral open bite: treatment and stability. Am J Orthod Dentofacial Orthop. 2010;137(5):701-711. doi:10.1016/j.ajodo.2007.11.037

22. Kiliaridis S, Katsaros C. The effects of myotonic dystrophy and Duchenne muscular dystrophy on the orofacial muscles and dentofacial morphology. Acta Odontol Scand. 1998;56(6):369-374. doi:10.1080/000163598428347

23. van den Engel-hoek L, de Groot IJ, Sie LT, et al. Dystrophic changes in masticatory muscles related chewing problems and malocclusions in Duchenne muscular dystrophy. Neuromuscular Disord. 2016;26 (6):354-360. doi:10.1016/j.nmd.2016.03.008

24. Morel-Verdebout C, Botteron S, Kiliaridis S. Dentofacial characteristics of growing patients with Duchenne muscular dystrophy: a morphological study. Eur J Orthod. 2007;29(5):500-507. doi:10.1093/ejo/cjm045

25. Matsuda S, Yoshimura H, Hamano T, Sano K. Post-traumatic trigeminal neuropathy caused by an orbital stab wound. J Craniofac Surg. 2017;28(1):e28-e30. doi:10.1097/SCS.0000000000003175 
26. Hes J, Baart JA. Sudden open bite resulting from hemarthrosis: report of a case. J Oral Maxillofac Surg. 1988;46(6):513-515. doi:10.1016/ 0278-2391(88)90428-4

27. Kaneda T, Nagayama M, Ohmori M, Minato F, Nakajima J, Shikimori M. Hemarthrosis of the temporomandibular joint in a patient with hemophilia B: report of case. J Oral Surg. 1979;37 (7):513-514.

28. Afroz S, Naritani M, Hosoki H, Matsuka Y. Posterior disc displacement of the temporomandibular joint: a rare case report. Cranio. 2018;1-6. doi:10.1080/08869634.2018.1509823

29. Chossegros C, Cheynet F, Guyot L, Bellot-Samson V, Blanc JL. Posterior disk displacement of the TMJ: MRI evidence in two cases Cranio. 2001;19(4):289-293. doi:10.1080/08869634.2001.11746180

30. Higginson JA, Bartram AC, Banks RJ, Keith DJW. Condylar hyperplasia: current thinking. Br J Oral Maxillofac Surg. 2018;56(8):655662. doi:10.1016/j.bjoms.2018.07.017

31. Wang BL, Yang C, Cai XY, et al. Malocclusion as a common occurrence in temporomandibular joint arthroscopic disc repositioning: outcomes at 49 days after surgery. J Oral Maxillofac Surg. 2011;69(6):1587-1593. doi:10.1016/j.joms.2010.10.019

32. Kai S, Kai H, Tabata O, Tashiro H. The significance of posterior open bite after anterior repositioning splint therapy for anteriorly displaced disk of the temporomandibular joint. Cranio. 1993;11(2):146-152. doi:10.1080/08869634.1993.11677956

33. Ng AT, Gotsopoulos H, Qian J, Cistulli PA. Effect of oral appliance therapy on upper airway collapsibility in obstructive sleep apnea. Am $J$ Respir Crit Care Med. 2003;168(2):238-241. doi:10.1164/ rccm.200211-1275OC

34. Rose EC, Staats R, Virchow C, Jonas IE. Occlusal and skeletal effects of an oral appliance in the treatment of obstructive sleep apnea. Chest. 2002;122(3):871-877. doi:10.1378/chest.122.3.871

35. Perez CV, de Leeuw R, Okeson JP, et al. The incidence and prevalence of temporomandibular disorders and posterior open bite in patients receiving mandibular advancement device therapy for obstructive sleep apnea. Sleep Breath. 2013;17(1):323-332. doi:10.1007/s11325-012-0695-1

36. Pliska BT, Nam H, Chen H, Lowe AA, Almeida FR. Obstructive sleep apnea and mandibular advancement splints: occlusal effects and progression of changes associated with a decade of treatment. J Clin Sleep Med. 2014;10(12):1285-1291. doi:10.5664/jcsm.4278

37. Teixeira AOB, Andrade ALL, Almeida RCDC, Almeida MAO. Side effects of intraoral devices for OSAS treatment. Braz J Otorhinolaryngol. 2018;84(6):772-780. doi:10.1016/j.bjorl.2017.09.003

38. Monteith BD. Altered jaw posture and occlusal disruption patterns following mandibular advancement therapy for sleep apnea: a preliminary study of cephalometric predictors. Int J Prosthodont. 2004;17(3):274-280.

39. Fransson A. A mandibular protruding device in obstructive sleep apnea and snoring. Swed Dent J Suppl. 2003;163:1-49.

40. Bondemark L. Does 2 years' nocturnal treatment with a mandibular advancement splint in adult patients with snoring and OSAS cause a change in the posture of the mandible? Am J Orthod Dentofacial Orthop. 1999;116(6):621-628. doi:10.1016/S0889-5406(99)70196-4

41. Pavlic A, Battelino T, Trebusak Podkrajsek K, Ovsenik M. Craniofacial characteristics and genotypes of amelogenesis imperfecta patients. Eur J Orthod. 2011;33(3):325-331. doi:10.1093/ejo/ cjq089

42. Ravassipour DB, Powell CM, Phillips CL, et al. Variation in dental and skeletal open bite malocclusion in humans with amelogenesis imperfecta. Arch Oral Biol. 2005;50(7):611-623. doi:10.1016/j. archoralbio.2004.12.003

43. Yanagita T, Kuroda S, Takano-Yamamoto T, Yamashiro T. Class III malocclusion with complex problems of lateral open bite and severe crowding successfully treated with miniscrew anchorage and lingual orthodontic brackets. Am J Orthod Dentofacial Orthop. 2011;139 (5):679-689. doi:10.1016/j.ajodo.2009.07.023
44. Bilodeau JE. Nonsurgical treatment of a Class III patient with a lateral open-bite malocclusion. Am J Orthod Dentofacial Orthop. 2011;140(6):861-868. doi:10.1016/j.ajodo.2010.09.032

45. Janson M, Janson G, Sant'Ana E, Tibola D, Martins DR. Orthognathic treatment for a patient with Class III malocclusion and surgically restricted mandible. Am J Orthod Dentofacial Orthop. 2009;136(2):290-298. doi:10.1016/j.ajodo.2007.01.039

46. Simon SS, Charlu AP, Chacko RK, Kumar S. A novel technique to correct multiplanar maxillary hypoplasia. J Clin Diagn Res. 2016;10(4):ZD09-ZD11. doi:10.7860/JCDR/2016/16599.7639

47. Mills JR. The problem of overbite in Class II, division 2 malocclusion. Br J Orthod. 1973;1(1):34-48. doi:10.1179/bjo.1.1.34

48. Lapatki BG, Mager AS, Schulte-Moenting J, Jonas IE. The importance of the level of the lip line and resting lip pressure in Class II, Division 2 malocclusion. J Dent Res. 2002;81(5):323-328. doi:10.1177/154405910208100507

49. Online mendelian inheritance in man [homepage on the Internet]. Available from: https://www.ncbi.nlm.nih.gov/omim. Accessed March $31,2019$.

50. Genetics Home Reference [homepage on the Internet]. Available from: https://ghr.nlm.nih.gov/. Accessed March 31, 2019.

51. Jacobson A, Evans WG, Preston CB, Sadowsky PL. Mandibular prognathism. Am J Orthod. 1974;66(2):140-171. doi:10.1016/00029416(74)90233-4

52. Liu H, Wu C, Lin J, Shao J, Chen Q, Luo E. Genetic Etiology in nonsyndromic mandibular prognathism. J Craniofac Surg. 2017;28 (1):161-169. doi:10.1097/SCS.0000000000003287

53. Yamaguchi T, Park SB, Narita A, Maki K, Inoue I. Genome-wide linkage analysis of mandibular prognathism in Korean and Japanese patients. J Dent Res. 2005;84(3):255-259. doi:10.1177/ 154405910508400309

54. Li Q, Li X, Zhang F, Chen F. The identification of a novel locus for mandibular prognathism in the Han Chinese population. J Dent Res. 2011;90(1):53-57. doi:10.1177/0022034510382546

55. Li Q, Zhang F, Li X, Chen F. Genome scan for locus involved in mandibular prognathism in pedigrees from China. PLoS One. 2010;5:9.

56. Jang JY, Park EK, Ryoo HM, et al. Polymorphisms in the Matrilin-1 gene and risk of mandibular prognathism in Koreans. J Dent Res. 2010;89(11):1203-1207. doi:10.1177/0022034510375962

57. Guan X, Song Y, Ott J, et al. The ADAMTS1 gene is associated with familial mandibular prognathism. J Dent Res. 2015;94(9):1196-1201. doi:10.1177/0022034515589957

58. Xue F, Rabie AB, Luo G. Analysis of the association of COL2A1 and IGF-1 with mandibular prognathism in a Chinese population. Orthod Craniofac Res. 2014;17(3):144-149. doi:10.1111/ ocr. 12038

59. Xue F, Wong R, Rabie AB. Identification of SNP markers on 1p36 and association analysis of EPB41 with mandibular prognathism in a Chinese population. Arch Oral Biol. 2017;152(1):867-872. doi:10.1016/j.archoralbio.2010.07.018

60. Toral-López J, González-Huerta LM, Messina Baas O, CuevasCovarrubias SA. A family with craniofrontonasal syndrome and a mutation (p.G151S) in the EFNB1 gene: expanding the phenotype. Mol Syndromol. 2016;7(1):32-36. doi:10.1159/000444771

61. Kantaputra PN, Pruksametanan A, Phondee N, et al. ADAMTSL1 and mandibular prognathism. Clin Genet. 2019;95(4):507-515. doi:10.1111/cge.13519

62. Zhou J, Lu Y, Gao XH, et al. The growth hormone receptor gene is associated with mandibular height in a Chinese population. $J$ Dent Res. 2005;84(11):1052-1056. doi:10.1177/1544059105084 01116

63. Nutrition classics. Archives of Internal Medicine, Volume. 64, October 1939: angina pectoris in hereditary xanthomatosis. By Carl Müller. Nutr Rev. 1987;45(4):113-115. doi:10.1111/j.1753-4887.198 7.tb02723.x 
64. Khachadurian AK. The inheritance of essential familial hypercholesterolemia. Am J Med. 1964;37(3):402-407. doi:10.1016/0002-9343 (64)90196-2
65. Endo A. A historical perspective on the discovery of statins. Proc Jpn Acad Ser B Phys Biol Sci. 2010;86(5):484-493. doi:10.2183/ pjab.86.484

\section{Publish your work in this journal}

Clinical, Cosmetic and Investigational Dentistry is an international, peer-reviewed, open access, online journal focusing on the latest clinical and experimental research in dentistry with specific emphasis on cosmetic interventions. Innovative developments in dental materials, techniques and devices that improve outcomes and patient

Submit your manuscript here: https://www.dovepress.com/clinical-cosmetic-and-investigational-dentistry-journal satisfaction and preference will be highlighted. The manuscript management system is completely online and includes a very quick and fair peer-review system, which is all easy to use. Visit http://www.dovepress.com/testimonials.php to read real quotes from published authors. 